\title{
Mechanical Properties of Micro- and Nanostructured Copper Films
}

\author{
N. Kosarev, M. Khazin, R. Apakashev, N. Valiev \\ The Ural State Mining University, Ekaterinburg, Russia \\ Email: parknedra@yandex.ru
}

Received June 2013

\begin{abstract}
Mechanical properties of electrodeposited and electroless copper with nano- and crystalline structure are considered. Grain diameters in films ranged from 0.06 to $8 \mu \mathrm{m}$. A model is described which takes into account the grain boundary hardening and density of dislocation.
\end{abstract}

Keywords: Nano- and Microcrystalline Materials; Hall-Petch Relation; Yield Point Stress; Grain Boundary Hardening Coefficient; Nonequilibrium Grain Boundaries

\section{Introduction}

Structural features of nanomaterials determine their unique properties. Properties of nanomaterials strongly depend from type of distribution, form, size and chemical composition of crystallites. Nanomaterials are used in practice due to their mechanical properties: resilience, plasticity, strength etc. The identification of regularities of influence of size effects to forming of nanomaterials' properties is one of the most important problems of nanostructural materials science.

In this paper copper films received by electroless and electrodeposit precipitation to metallic and dielectric substrates are researched. Thin structure of copper was studied by the method of transmission electron microscopy on the electronic microscope TESLA BS 500. Coverings are thinned by two-sided electrodeposite etching with using the method of "window" in 50\% water solution of orthophosphoric acid.

\section{Experiment}

The studying of structure is conducted from the broadening of the lines on received polycrystalline X-ray pictures. The record of intensity distribution curves of model and samples is conducted on diffract meter "DRON-3" with use of nickel-filtered characteristic $\mathrm{K} \alpha$ iron emission. For calculation of characteristics of thin structure we used seven Fourier coefficients $(t=0,1, \cdots, 6)$. Studying of elemental composition of the conductors is conducted by atomic adsorption method on the spectrophotometer "Perkin Elmer" model 403. For researching of mechanical properties the copper films is separated from the substrate. Mechanical properties of free copper films were determined at tensile tests on the breaking machine with record of strain diagrams.

In polycrystalline metals the change in the flow stress $\left(\sigma_{\mathrm{T}}\right)$ from the grain diameters $(d)$ is described by HallPetch relation:

$$
\sigma \varphi_{y}=0+k d^{-1 / 2}
$$

$\sigma_{0}$ : tension which characterizes plastic deformation resistance, $k_{\mathrm{y}}$ : coefficient which characterizes the influence of grain boundaries on hardening.

Received experimental results of research of dependence of flow stress of electroless and electrodeposited precipitated copper from the grain diameters (according to $\mathrm{d}^{-1 / 2}$ ) averaged by linear dependence (Figure 1).

Extrapolation of dependence $\sigma \sigma(z) \quad$ to $\varepsilon=0$ is allowed to estimate the value of shear stress $\sigma_{f}$. Results for electroless and electrodeposited precipitated copper are concordant with data for the copper which got by casting method and vacuum deposition method [1-3]. A Table 1 shows coefficients of the Equation (1) which adequate to samples received by various methods.

Value $\sigma_{f}$ or $\sigma o$ depends from the presence of obstacles for promotion of dislocations in sliding places: friction forces of Peierls, cluster of dislocations, impurity atoms and other defects). Coefficient $k_{\mathrm{y}}$ characterizes a difficulty of transmission of strains from grain to grain [4]. Elemental composition of precipitated conductors determined y atomic adsorption method similar to copper grade M2 (mass fraction of the copper 99.70\%). At the same time the samples considered in works $[2,3]$ similar 


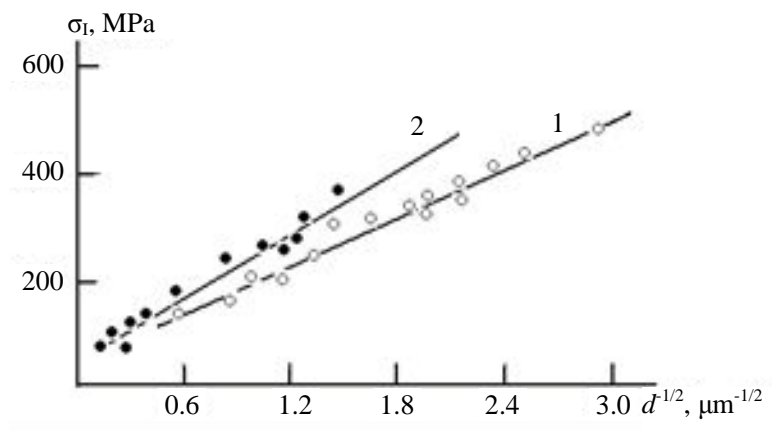

Figure 1. The dependence of the flow stress of copper from the grain diameters: 1 . electroless precipitated films, 2 . electrodeposited precipitated films.

Table 1. Values of Hall-Petch coefficients for copper received by various methods.

\begin{tabular}{|c|c|c|c|c|}
\hline $\begin{array}{l}\text { Method of } \\
\text { producing }\end{array}$ & $\begin{array}{l}\text { Range of grain } \\
\text { diameters, } \mu \mathrm{m}\end{array}$ & $\sigma_{f}, \mathrm{MPa}$ & $\sigma_{0}, \mathrm{MPa}$ & $k_{y}, \mathrm{MPa} \mathrm{m}^{1 / 2}$ \\
\hline Casted [5] & $500-1000$ & - & 26.10 & 0.11 \\
\hline Casted [4] & $0.8-3.4$ & 3.5 & - & 0.14 \\
\hline $\begin{array}{l}\text { Condensation } \\
\text { in vacuum [3] }\end{array}$ & $0.056-8.4$ & 6.4 & - & 0.15 \\
\hline \multicolumn{5}{|c|}{$\begin{array}{l}\text { Electrodeposited } \\
\text { precipitation }\end{array}$} \\
\hline electrolyte 1 & $0.5-5$ & 6.2 & 37.31 & 0.17 \\
\hline electrolyte 2 & $0.8-8$ & 6.1 & 32.74 & 0.15 \\
\hline \multicolumn{5}{|l|}{$\begin{array}{l}\text { Electroless } \\
\text { precipitation }\end{array}$} \\
\hline liquor 1 & $0.06-2$ & 6.5 & 27.21 & 0.16 \\
\hline liquor 2 & $0.10-2$ & 6.4 & 25.16 & 0.15 \\
\hline liquor 3 & $0.06-1,5$ & 6.5 & 36.23 & 0.18 \\
\hline liquor 4 & $0.04-2$ & 6.7 & 28.14 & 0.16 \\
\hline Casted [6] & $1-10$ & & & $0.1-0.13$ \\
\hline Casted [6] & 0,1 & & & 0.06 \\
\hline Casted [6] & 0.07 & & & 0.05 \\
\hline Casted [7] & 50 & & & 0.12 \\
\hline $\begin{array}{l}\text { Casted and } \\
\text { deformed [7] }\end{array}$ & 0.18 & & & 0.09 \\
\hline Casted [8] & 50 & & 70 & 0.28 \\
\hline $\begin{array}{l}\text { Casted and } \\
\text { deformed [8] }\end{array}$ & 0.30 & & 25 & 0.19 \\
\hline
\end{tabular}

to the copper grade MOO (mass fraction of the copper 99.99\%) [5].

Increasing of coefficient $\sigma f$ with vacuum condensates may be connected with high concentration of point defects formed at condensation of copper, i.e. due to the method of receiving and also entering of the evaporator material to the condensate [3].

Electroless precipitating of copper foil was conducted at $310-320 \mathrm{~K}$. Density properties of received samples after annealing are exceeding values for massive copper.
Therefore we propose decrease in purity of copper 99,99 to $99.95 \%$, i.e. the presence of impurities determines observable increasing of coefficients' meanings $\sigma_{f}$ and $k_{\mathrm{y}}$. This proposal confirmed by the data about electrodeposited copper (Table 1). Injection of some organic additives led to conversion from equiaxed structure to columnar structure, thereafter temporary tensile strength and yield point stress plasticity have reduced, and electrical resistivity has increased.

\section{Result}

Estimation of density of dislocations at experimental values of flow stress is consistent with data received from broadening of the diffraction peaks. Increasing of film thickness and copper grain diameters is lead to reducing of density of dislocations, thereafter flow stress and temporary tensile strength have reduced and plasticity has increased.

Theory of the strain hardening is connect flow stress and density of dislocations with relation $[4,8]$

$$
\sigma \sigma{ }_{f}+\alpha G b^{1 / 2} \text {, }
$$

$\sigma_{f}$ : shear stress, $G$ : shear modulus, $b$ : Burgers vector, $\rho$ : density of dislocations, $\alpha$ : constant close to 1 .

Basis of this model is proposal about the path length of dislocation l s proportionally to average grain diameter. As far as plastic deformation and density of dislocations are connected by relation [8]

$$
\varepsilon=l b \rho,
$$

so density of dislocations is

$$
\rho=a_{1} \varepsilon / b d
$$

$a_{1}$ is a constant.

Placing relation (4) in (2), we get

$$
\sigma \in(\varepsilon)_{0}+a_{2} G b^{1 / 2} d^{-1 / 2},
$$

Equation (5) is similar to Hall-Petch relation, if we mark

$$
k_{\mathrm{y}}=a_{2} G(b){ }^{1 / 2} \text {. }
$$

From (6) it is follows that value of coefficient $k_{y}$ must to increase with increasing of the deformation degree. Such dependence is observed well at $77 \mathrm{~K}$, but almost no at the room temperature.

\section{Discussion}

In our time there are some theories explaining the change of value of yield point stress after injection of non-interacting second-phase particles to the matrix. Two cases of interaction of dislocations with particles are possible:

a) dislocations cut the particles on early stages of deformation-Ansell-Lenel model [6]; 
b) dislocations bend and then follow between particles leaving concentric dislocation loops around them-Orovan model $[4,8]$.

Most theoretical justification and experimental confirmation are gotten by Orovan model specified by Ashby [9].

Releases of the second phase follow to significant increasing of flow stress and deformation hardening, resulting in the first stage suppression on the hardening curve. In polycrystalline except direct interaction of dislocations with particles grain boundary hardening effects due to the grinding of structure are essential. Acting as barriers for movement of dislocations grain boundaries is providing additional hardening [8], which add to hardening by Orovan. At the same time indirect effect of second-phase through the grinding of structure can significantly exceed its direct strengthening effect, i.e. the main effect created by second phase is the grinding of structure.

Thus in film systems the main result of hardening is determined by indirect effect of second-phase particles: high dispersion of particles and grinding of structure when a small volume fraction of particles. In a theory about plastic deformation of inhomogeneous material the density of dislocations is connected with solid flat particles at Ashby [8] as

$$
\rho \rho \rho,{ }_{c}+{ }_{g}
$$

$\rho_{\mathrm{c}}$ : density of statistically distributed dislocations, $\rho_{\mathrm{g}}$ : density of geometrically needed dislocations.

In polycrystalline grain boundaries may be considered as analogy of flat particles as almost impassable barriers for dislocations. In common case it is known that the way of influence grain diameters to physical and mechanical properties is in the barrier effect of grain boundaries at a slip [4]. In fine-grained materials the most likely way of plastic deformation is a slip.

Usually common density of dislocations in a material is proportional to degree of plastic deformation $[4,8]$. In this case the tension ubecause of dislocations and dislocation loops circling particles obstructs further movement of the slide and has an influence to issues of dislocations. Because of this in the early stages of deformation yet the strain hardening rate $\mathrm{d} \sigma / \mathrm{d} \varepsilon$ will strongly higher than for massive alloys. As a result there is intensive increase of dislocation density with increase of degree of deformation. Then we may get the equality for dispersion-hardened material provided that geometrically necessary dislocations are distributed homogeneously:

$$
\rho 4 \mathrm{~F} F \quad n \quad b d \text {, and } \rho \varepsilon=A n+\rho_{o},
$$

$\Gamma$ : shear deformation.

Replacing $\Gamma$ through $m \varepsilon$ ( $m$ : Tailor factor) and marking value $4 \mathrm{mn} / \mathrm{b}$ through $B$, we get

$$
\rho=\rho(+\varepsilon, A+B \boldsymbol{d})-\quad n
$$

$\rho_{\mathrm{o}}$ : density of dislocations in the infinitely large grain. Solving (2) and (8) in common, we get equation

$$
\sigma \phi\left(\oplus_{f}+a G b_{\mathrm{o}}+A \varepsilon n+\right)^{1 / 2} .
$$

Let's consider possible special cases.

1) When $n=1$, we ignore value $\rho_{\mathrm{o}} \cong 0$, this equality transfers to equation got by Van der Beikel [9] for plastically deforming metals.

2) In case of fine-grained material $\mathrm{A}<B d-1$. If we ignore value $\rho_{\mathrm{o}} \cong 0$ and mark $(a G b)\left(B n^{1 / 2}=k_{\mathrm{y}}\right.$, then we get Hall-Petch equation.

3) In case of hard-grained material $\mathrm{A}>B d-1$ and $\rho_{\mathrm{o}} \cong$ 0 we get

$$
\sigma \phi\left(=\rho_{f}\right)\left(+a G b \quad A \varepsilon n+{ }_{0}\right)^{1 / 2} .
$$

Analysis of Equation (9) shows that observed strength properties of electroless precipitated copper caused by high density of dislocations and ultrafine structure. Because of this, a metal possess of low plasticity was also watched by experiments for various materials and alloys. So Equation (9) may be used in a wide range of grains diameters and density of dislocations.

\section{REFERENCES}

[1] B. N. Smirnov and M. L. Khazin, "Fol'ga Dlya Pechatnyh Plat/Foil for Printed Circuit Boards," UB of RAS, Ekaterinburg, 2003, p. 376.

[2] K. Wang, N. R. Tao, G. Liu, J. Lu and K. Lu, "Plastic strain-Induced Grain Refinement at the Nanometer Scale in Copper,” Acta Materialia, Vol. 54, 2006, p. 5281. http://dx.doi.org/10.1016/j.actamat.2006.07.013

[3] L. S. Palatnik and V. K. Sorokin, "Materialovedenie v Mikroelektronike, Materials Science in Microelectronics,” Energiya, Moscow, 1977, p. 280.

[4] M. L. Bernshtein and V. A. Zaimovskij, "Mekhanicheskiye Svoistva Metallov, Mechanical Properties of Metals,” Metallurgiya, Moskow, 1979, p. 495.

[5] O. E. Osintsev and V. N. Phyodorov, "Med' i Mednye Splavy. Otechestvennye i Zarubezhnye Marki, Copper and Copper Alloys,” Russian and Foreign Brands, Mashinostroenie, Moscow, 2004, p. 215.

[6] M. A. Meyers, A. Mishra and D. J. Benson, "Mechanical Properties of Nanocrystalline Materials," Progress in Materials Science, Vol. 51, 2006, pp. 427-556. http://dx.doi.org/10.1016/j.pmatsci.2005.08.003

[7] A. V. Nokhrin, V. N. Chuvildeev, V. I. Kopylov, et al., "Sootnoshenie Holla-Petcha v nano-i Microcristallicheskih Metallah, Poluchennyh Metodami Intensivnogo Plasticheskogo Deformirovaniya, Hall-Petch Ratio in Nanoand Microcrystalline Metals Received by Methods of Intensive Plastic Deformation," Vestnik Nizhegorodskovo Universiteta Imeni N. I. Lobachevskogo, Vol. 5, No. 2, 2010, pp. 142-146. 
[8] R. B. Khonikomb, "Plasticheskaya Deformatsiya Metallov, Plastic Deformation of Metals,” Mir, Moscow, 1972, p. 408.
[9] A. Van der Beukel, "Grain Size Dependence of the Dislocation in Cold-Worked,” Scr. Met., No. 9, 1978, pp. 809-817. 